\title{
Possibility of direct electricity production from waste canola oil
}

\author{
Paweł P. Włodarczyk ${ }^{1, *}$, Barbara Włodarczyk $^{1}$, and Antonina Kalinichenko ${ }^{1}$ \\ ${ }^{1}$ University of Opole, Department of Process Engineering, Dmowskiego Street 7-9, 45-365 Opole, Poland
}

\begin{abstract}
Powering high-efficiency devices, such as fuel cells, with waste products will allow for a broader development of renewable energy sources and utilisation of by- products. This publication presents the possibility of electrooxidation of the emulsion of waste rapeseed oil, prepared on the basis of the detergent Syntanol DS-10. The process of electrooxidation was carried out on platinum electrode in alkaline $(\mathrm{KOH})$ and acidic $\left(\mathrm{H}_{2} \mathrm{SO}_{4}\right)$ electrolyte, in the temperature range of 293-333 K. In each analysed case the process of electrooxidation took place. The maximum current density obtained was $7 \mathrm{~mA} \cdot \mathrm{cm}^{-2}$. Thus, it has been shown that it is possible to generate electricity directly from the emulsion of the waste rapeseed oil.
\end{abstract}

\section{Introduction}

Today's energy production is based mainly on crude oil, coal, natural gas and nuclear energy. But in the last few years alternative energy sources have also been developing very fast. There is use of photovoltaic cells, solar collectors, heat pumps, wind turbines and more. One of these sources is also fuel cells (FC). The actual efficiency of FCs is up to $80-90 \%[1,2]$. Thus, the FCs are the most efficient power devices. Moreover, the main advantages of fuel cells are zero or low negative influence on the environment and silent operation [3, 4]. Most often the hydrogen is used as fuel for FCs [2-4, 5]. However, there are problems with cheap production and storage of this fuel, and that is the reason for the search of new fuels for FCs, including biofuels [3, 6-9]. Previous studies by the authors [10-15] have shown a possibility of electrooxidation (in various electrolytes) of petroleum derivatives and vegetable oils, e.g. canola oil, sun flower oil or grape seed oil. Canola seed oil is often used as additive for biodiesel fuel, especially as a blend with petroleum diesel fuel. Almost all manufacturers of diesel vehicles and engines have approved the use of B5 (a blend containing 5\% of biodiesel), some approve the use of B20 blends $(20 \%$ biodiesel) or higher, up to $100 \%$ biodiesel (B100) [16, 17]. Also, significant amounts of waste canola oils are produced everyday. Therefore, an attempt to use waste canola oil as fuel for fuel cells seems justified. In this case, electrooxidation of waste canola oil should be carried out in order to determine the basic ability of this substance to electrooxidate on platinum electrode. Theoretically, the current density can be calculated using the Butler-Volmer exponential function [18]

$$
i=A \cdot i_{0} \cdot\left(e^{\left(\frac{\alpha_{a} n F}{R T}\left(E-E_{q}\right)\right)}-e^{\left(\frac{\alpha_{c} n F}{R T}\left(E-E_{q}\right)\right)}\right)
$$

where $i$ is electrode current density $\left(\mathrm{A} \cdot \mathrm{m}^{-2}\right) ; i_{0}$ is exchange current density $\left(\mathrm{A} \cdot \mathrm{m}^{-2}\right) ; R$ is universal gas constant; $E$ is electromotive force at the terminals of the real cell $(\mathrm{V}) ; E_{e q}$ is equilibrium potential $(\mathrm{V}) ; \alpha_{a}$ is the so-called anodic charge transfer coefficient; $\alpha_{c}$ is the socalled cathodic charge transfer coefficient; $A$ is electrode active surface area $\left(\mathrm{m}^{2}\right) ; n$ is number of electrons involved in the electrode reaction; $F$ is faraday constant per volt gram equivalent $(\mathrm{kJ})$;

or in a more compact form [18]

$$
i=i_{0} \cdot e^{\left(K \cdot \eta_{a c t}\right)}
$$

where $\eta_{\text {act }}$ is activation overpotential (V); $K$ is the factor of dependence of activation overpotential on reaction speed.

But, in real conditions the choice of fuel (or catalyst) is mainly carried out by experimental methods. The work covered the research on obtaining electricity from waste canola oil electrooxidation. This work covers the analysis of possibility of powering FCs with waste canola oil. The possibility of powering FCs with waste canola oil will allow for further development of renewable energy devices and will enable to eliminate or reduce the emissions of toxic substances.

\section{Material and Methods}

Tested canola oils came from five places (where it is used for frying). Oils were mixed to obtain a homogeneous sample. Next, the prepared oil was filtered in standard automotive fuel filter to eliminate solid substances and other pollution. In case of using waste canola oil as fuel for fuel cells, conducting the electric current is very important. Waste canola oil is a hydrophobic substance and does not conduct the electric current. In order to cause the conduction, an

* Corresponding author: pawel.wlodarczyk@uni.opole.pl 
intermediate agent to solve waste canola oil in water was used. In order to cause the conduction, an intermediate agent to solve waste canola oil in water was used. Due to its excellent emulsification properties, Syntanol DS-10 was used as the detergent [19]. Syntanol DS-10 is characterized by high superficial activity, dispersion, solubilisation capabilities and emulgation [20,21]. After the electrooxidation of the emulsion, Syntanol DS-10 can be degraded, e.g. promoted by energy transfer reactions or by bacteria $[22,23]$. Investigated waste canola oil emulsion (WCOE) was obtained by mixing, in various ratios of water, waste canola oil and the detergent. WCOE was obtained with the use of a mechanical stirrer, with the speed of about $1200 \mathrm{rpm}$ [10-15]. Concentration of canola oil and Syntanol DS-10 was equal to $0.0100 \%, 0.025 \%$ and $0.0500 \%$. Emulsion stabilization time was about 6-8 hours (depending on the temperature). The Fig. 1 shows scheme of emulsion preparation.

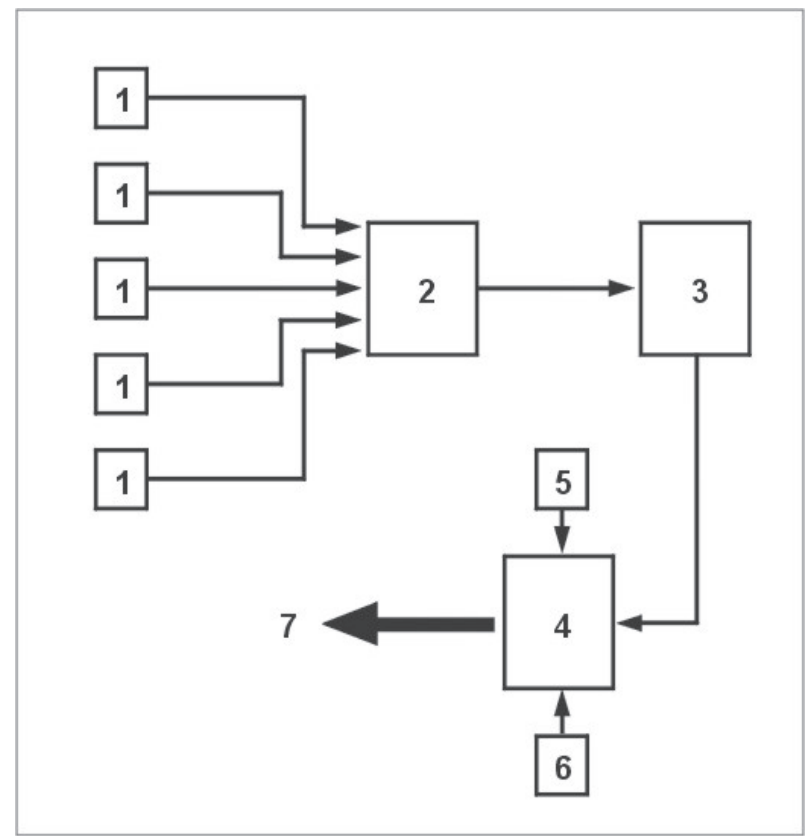

Fig. 1. Scheme of emulsion preparation

1 - points of acquisition of the waste canola oil samples, 2 mixing of waste canola oil samples, filtration of mixed waste canola oil, 4 - WCOE preparation (by mixing), 5 - water, 6 detergent (Syntanol DS-10), 7 - WCOE for measurements.

Measurements were done by the method of polarizing curves of electrooxidation of waste canola oil emulsion in glass vessel, on a smooth platinum electrode in aqueous solution of $\mathrm{KOH}$ and $\mathrm{H}_{2} \mathrm{SO}_{4}$ electrolytes. The electrode surface area was equal to $6.28 \mathrm{~cm}^{2}$. Platinum was used as the catalyst of working electrode, due to its excellent catalytic properties [18], while saturated calomel electrode (SCE) was used as a reference electrode. The measurements were conducted at various temperatures 293, 303 and $333 \mathrm{~K}$. Electrochemical measurements were performed in a glass cell with potentiostat connected to a computer. Potentiostat AMEL System 5000 was used in the research. The Fig. 2 shows the scheme of glass vessel with electrodes.

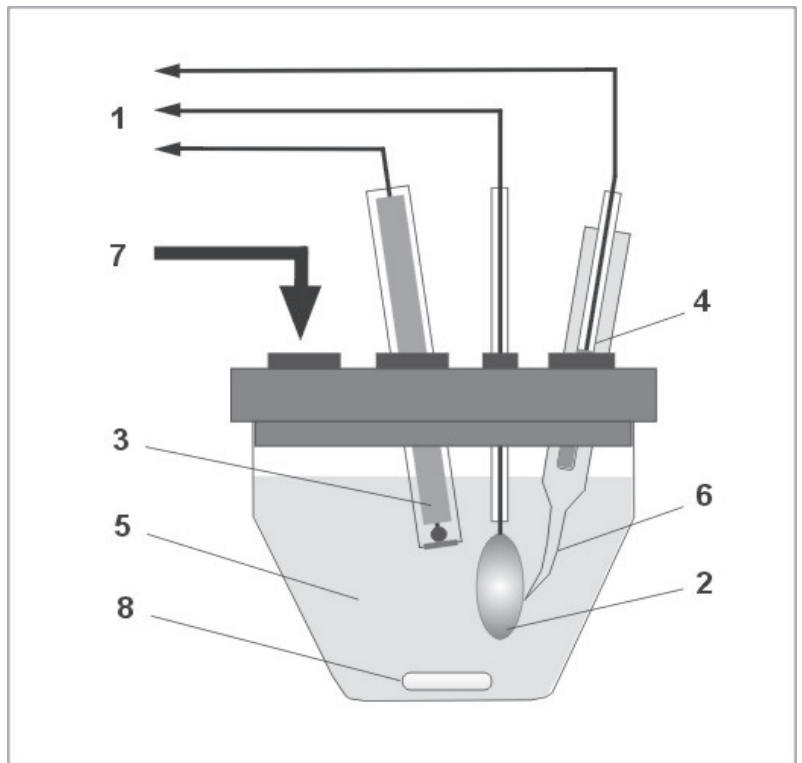

Fig. 2. Scheme of glass vessel with electrodes 1 - to potentiostat, 2 - working electrode $(\mathrm{Pt}), 3$ - auxiliary electrode, 4 - reference electrode (SCE), 5 - electrolyte $(\mathrm{KOH}$ or $\mathrm{H}_{2} \mathrm{SO}_{4}$ ), 6 - Luggin capillary, 7 - WCOE, 8 - stirrer bar.

The Fig. 3 shows scheme of measurement position.

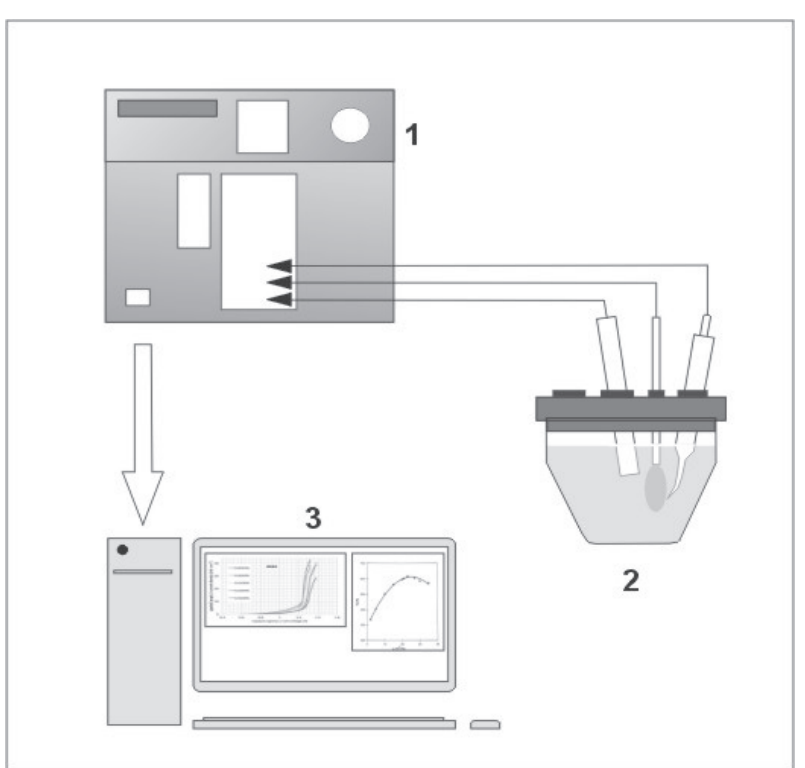

Fig. 3. Scheme of measurement position 1 - potentiostat, 2 - glass vessel, 3 - computer.

\section{Results}

First, the measurements were taken on electrooxidation of Syntanol DS-10 in electrolyte (aqueous solution of $\mathrm{KOH}$ and $\mathrm{H}_{2} \mathrm{SO}_{4}$ ), for various concentrations of the detergent at temperatures of $293-333 \mathrm{~K}$. Next, the measurements were taken on electrooxidation of WCOE in aqueous solution of $\mathrm{KOH}$ and $\mathrm{H}_{2} \mathrm{SO}_{4}$ electrolytes, for various concentrations of the detergent at temperatures of $293-333 \mathrm{~K}$. The comparison of these two processes (electrooxidation of Syntanol DS-10 and WCOE) allowed to determine whether the electricity is generated form the electrooxidation of the oil, or just from the 
detergent. Figs. 4-6 shows electrooxidation of WCOE in $\mathrm{KOH}$ at the temperature of $293-333 \mathrm{~K}$.

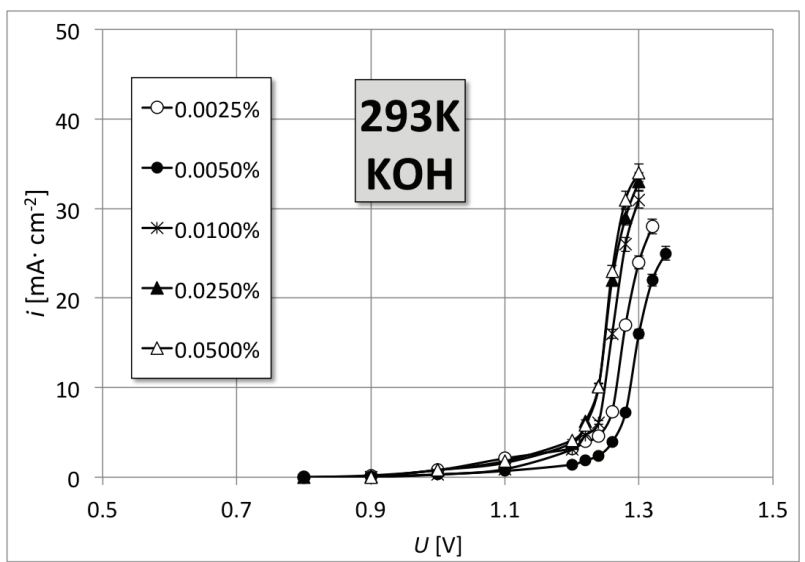

Fig. 4. Polarization curves of WCOE electrooxidation in $0,1 \mathrm{n}$ concentration of electrolyte $\mathrm{KOH}$ at $293 \mathrm{~K}$ - concentration of canola oil was equal to $0.0100 \%, 0.025 \%$ and $0.0500 \%$.

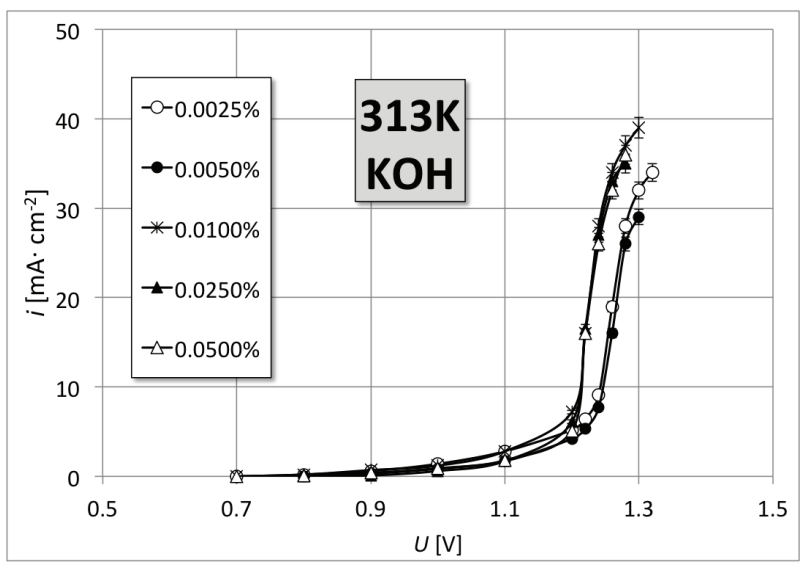

Fig. 5. Polarization curves of WCOE electrooxidation in $0,1 \mathrm{n}$ concentration of electrolyte $\mathrm{KOH}$ at $313 \mathrm{~K}$ - concentration of canola oil was equal to $0.0100 \%, 0.025 \%$ and $0.0500 \%$.

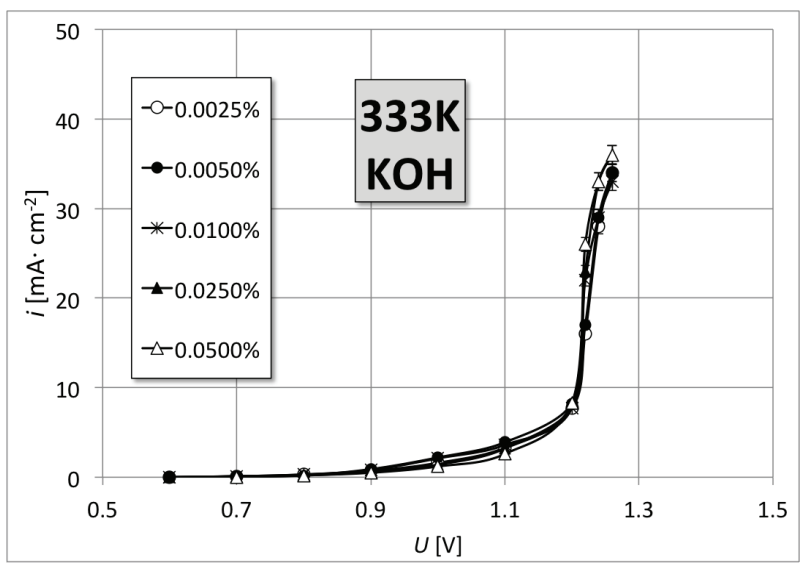

Fig. 6. Polarization curves of WCOE electrooxidation in $0,1 \mathrm{n}$ concentration of electrolyte $\mathrm{KOH}$ at $333 \mathrm{~K}$ - concentration of canola oil was equal to $0.0100 \%, 0.025 \%$ and $0.0500 \%$.

Figs. 7-9 show electrooxidation of WCOE in $\mathrm{H}_{2} \mathrm{SO}_{4}$ at the temperature $293-333 \mathrm{~K}$.

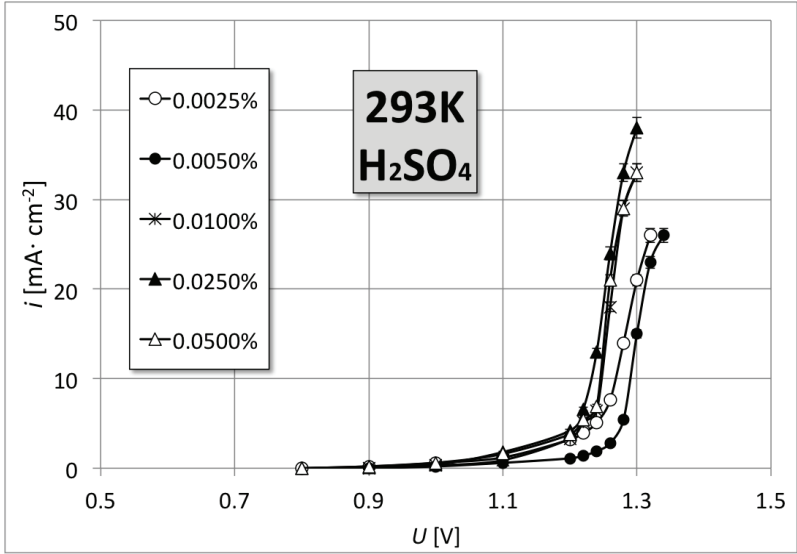

Fig. 7. Polarization curves of WCOE electrooxidation in $0,1 \mathrm{n}$ concentration of electrolyte $\mathrm{H}_{2} \mathrm{SO}_{4}$ at $293 \mathrm{~K}$ - concentration of canola oil was equal to $0.0100 \%, 0.025 \%$ and $0.0500 \%$.

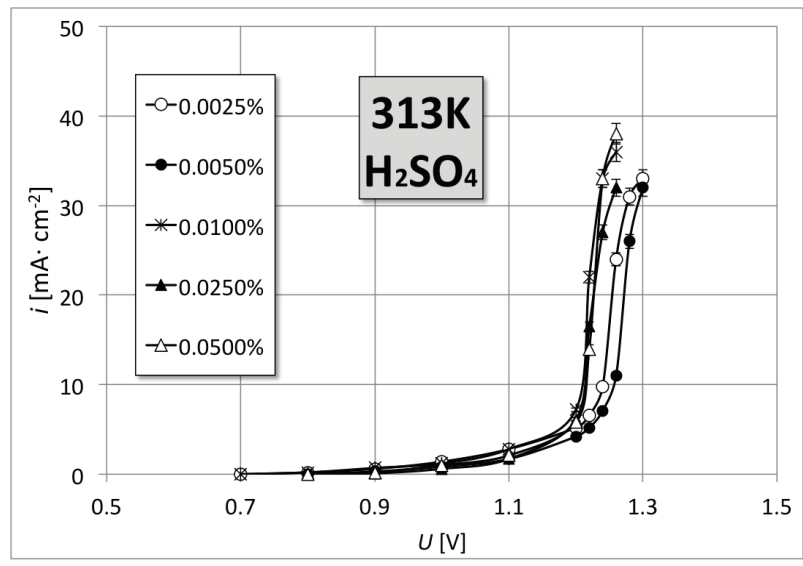

Fig. 8. Polarization curves of WCOE electrooxidation in $0,1 \mathrm{n}$ concentration of electrolyte $\mathrm{H}_{2} \mathrm{SO}_{4}$ at $313 \mathrm{~K}$ - concentration of canola oil was equal to $0.0100 \%, 0.025 \%$ and $0.0500 \%$.

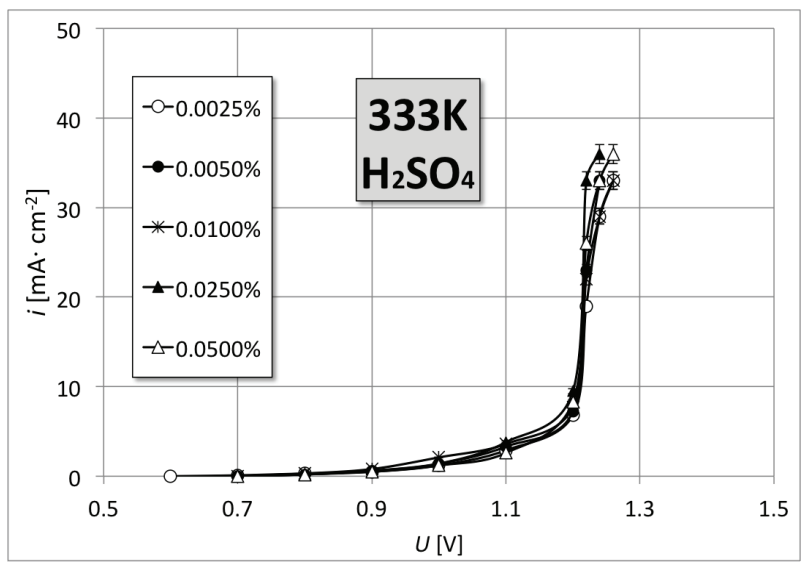

Fig. 9. Polarization curves of WCOE electrooxidation in $0,1 \mathrm{n}$ concentration of electrolyte $\mathrm{H}_{2} \mathrm{SO}_{4}$ at $333 \mathrm{~K}$ - concentration of canola oil was equal to $0.0100 \%, 0.025 \%$ and $0.0500 \%$.

\section{Conclusions}

The use of used oil to generate electricity in fuel cells would allow to develop the management of waste substances in a way that ensures low negative impact on 
the environment. Analysis of data from the measurements has shown the validity of the research undertaken in order to use the analyzed oil for energy production without the process of combustion. Potential of working electrode was establishing in about 22 minutes and was badly reproducible. Stationary, currentfree real potential depends on canola oil concentration and is included in potentials range of $0.60-1.28 \mathrm{~V}$. These values are very close to the values obtained with pure canola oil [14]. To ascertain that the emulsion (and not the detergent) was electrooxidated, measurements of electrooxidation process run in the scope of kinetics, but the potential on the electrode is low and establishes in a long period of time. The highest results of current density $\left(7 \mathrm{~mA} \cdot \mathrm{cm}^{-2}\right)$ were obtained at the temperature of $333 \mathrm{~K}$ for acid electrolyte. But the electrooxidation of WCOE occurred for all temperatures (293-333K), for all concentrations of waste canola oil, and for both electrolytes ( $\mathrm{KOH}$ and $\left.\mathrm{H}_{2} \mathrm{SO}_{4}\right)$. Current density during the electrooxidation of WCOE in acid electrolyte $\left(\mathrm{H}_{2} \mathrm{SO}_{4}\right)$ is slightly greater $\left(0.1-0.9 \mathrm{~mA} \cdot \mathrm{cm}^{-2}\right)$ than the current density during WCOE electrooxidation in alkaline electrolyte $(\mathrm{KOH})$. At all measurement attempts, electrooxidation in the acid electrolyte occurred more efficiently than in the alkaline electrolyte - the measurements were more reproducible. With the temperature above $333 \mathrm{~K}$, the first electrooxidation of Syntanol DS-10 takes place, and only then - of canola oil emulsion. For this reason, to ensure the occurrence of the process of electrooxidation in fuel cells (with $\mathrm{KOH}$ or $\mathrm{H}_{2} \mathrm{SO}_{4}$ electrolyte) powered with emulsion of waste rapeseed oil, the temperature of $333 \mathrm{~K}$ should not be exceeded.

It has been demonstrated that using the detergent Syntanol DS-10 to prepare the emulsion of waste canola oil allows for the electrooxidation of WCOE in aqueous solution of $\mathrm{KOH}$ and $\mathrm{H}_{2} \mathrm{SO}_{4}$, and thus enables direct conversion of waste canola oil into electrical energy (3-7 $\left.\mathrm{mA} \cdot \mathrm{cm}^{-2}\right)$. Therefore, a fundamental possibility of electrooxidation (electricity production) of waste canola oil on electrode (with platinum catalyst) in alkaline (aqueous solution of $\mathrm{KOH}$ ) and acid (aqueous solution of $\mathrm{H}_{2} \mathrm{SO}_{4}$ ) electrolyte was shown in this paper. The next stage of the research should be the analysis of the composition of the emulsion after electrooxidation, as well as the selection of a suitable catalyst.

\section{References}

1. R. O'Hayre, S-W. Cha, W. Colella, F. B. Prinz, Fuel Cell Fundamentals (John Wiley \& Sons, Hoboken, 2005)

2. D. Stolten, Hydrogen and fuel cells. Fundamentals, Technologies and Applications, (Wiley-VCH, Weinheim, 2010)

3. J. Larminie, A. Dicks, Fuel cell system explained (John Wiley \& Sons, Hoboken, 2003)

4. G. Hoogers, Fuel Cell Technology Handbook (CRC Press, Boca Raton, 2004)
5. J. Rifkin, The Hydrogen Economy (Jeremy $\mathrm{P}$. Tarcher/Penguin, New York 2003)

6. D. K. Ross, Vacuum 80 (10), 1084-1089 (2006)

7. A. Hamnett, Catalysis Today 38 (4), 445-457 (1997)

8. J. Milewski, J. Lewandowski, J. Power Technol. 93 (5), 347-353 (2013)

9. J. Milewski, K. Michalska, A. Kacprzak, J. Power Technol. 93 (3), 161-168 (2013)

10. P. P. Włodarczyk, B. Włodarczyk, J Power Technol. 93 (5), 394-396 (2013)

11. P. P. Włodarczyk, B. Włodarczyk, Infrast. Ecol. Rural Areas 4 (1), 1071-1080 (2016)

12. P. P. Włodarczyk, B. Włodarczyk, Diagnosing of the Environment Condition, Research Methods Forecasts, Works of Ecology Commission and Environmental Protection, Scientific Society of Bydgoszcz, 10, 205-216 (2016)

13. P. P. Włodarczyk, B. Włodarczyk, Ecol. Eng. 18 (1), 65-70 (2017)

14. P. P. Włodarczyk, B. Włodarczyk, J. Power Technol. 96 (6), 459-462 (2016)

15. P. P. Włodarczyk, B. Włodarczyk, New Trends in Management and Production Engineering Regional, Cross-border and Global Perspectives, 188-198 (Shaker Verlag, Aachen, 2016)

16. J. Sheehan, V. Camobreco, J. Duffield, M. Graboski, H. Shapouri, An overview of biodiesel and petroleum diesel life cycles, National Renewable Energy Laboratory, Prepared for U.S. Department of Energy's Office of Fuels Development and U.S. Department of Agriculture's Office of Energy (1998)

17. J. Van Gerpen, Fuel Process. Technol. 86 (10), 1097-1107 (2005)

18. J.O'M. Bockris, A.K.N. Reddy, Modern electrochemistry (Kulwer Academic/Plenum Publishers, New York, 2000)

19. Iu. I. Sakharov, E. G. Rastiannikov, G. M. Verbitskaia, L. N. Tarasova, Vopr Pitan. 4, 75-7 (1975)

20. A. Survila, Z. Mockus, S. Kanapeckaite, M. Samulevičienè, Electrochimica Acta 50 (14), 28792885 (2005)

21. O. Paraska, S. Karvan, Technical Transactions. Mechanics, Cracow University of Technology Press, 8 (107), 203-210 (2010)

22. A. V. Kravchenko, A. G. Rudnitskii, A. F. Nesterenko, V. S. Kublanovskii, Ukrainian Chemistry Journal C/C of Ukrainskii Khimicheskii Zhurnal, 60 (11), 11-13 (1994)

23. O. V. Ignatov, Iu. V. Shalunova, L. V. Panchenko, O. V. Turkovskaia, N. M. Ptichkina, Prikl Biokhim Mikrobiol. 31 (2), 220-223 (1995) 